\title{
Protein destruction by atmospheric pressure glow discharges
}

\author{
X. T. Deng and J. J. Shi \\ Department of Electronic and Electrical Engineering, Loughborough University, Loughborough, \\ Leicestershire LE11 3TU, United Kingdom \\ H. L. Chen \\ MRC Toxicology Unit, University of Leicester, Leicester, Leicestershire LE1 9HN, United Kingdom \\ M. G. Kong ${ }^{\text {a) }}$ \\ Department of Electronic and Electrical Engineering, Loughborough University, Loughborough, \\ Leicestershire LE11 3TU, United Kingdom
}

(Received 27 July 2006; accepted 13 November 2006; published online 4 January 2007)

\begin{abstract}
It is well established that atmospheric pressure glow discharges are capable of bacterial inactivation. Much less known is their ability to destruct infectious proteins, even though surgical instruments are often contaminated by both bacteria and proteinaceous matters. In this letter, the authors present a study of protein destruction using a low-temperature atmospheric dielectric-barrier discharge jet. Clear evidences of protein removal are presented with data of several complimentary experiments using scanning electron microscopy, electron dispersive x-ray analysis, electrophoresis, laser-induced fluorescence microscopy, and protein reduction kinetics. Considerable degradation is observed of protein fragments that remain on their substrate surface after plasma treatment. (C) 2007 American Institute of Physics. [DOI: 10.1063/1.2410219]
\end{abstract}

Protein removal represents a critically important challenge in medical sterilization, as highlighted by the link of residual tissue contamination of neurosurgical instruments to iatrogenic Creutzfeldt-Jakob diseases (CJD). ${ }^{1}$ Prion proteins of CJD are resistant to all conventional decontamination procedures and have consequently forced the strategy of singleuse surgical instruments to control the risk of cross contamination. For healthcare facilities, this is unsustainably expensive but has been the only risk-control option for the past 20 years. While prion contamination remains an extremely serious concern for public health, it offers major research opportunities for low-temperature gas plasma physics. Indeed encouraged by their potential as a bactericidal technique, ${ }^{2}$ low-temperature gas discharges have been studied extensively for bacterial inactivation both in a vacuum chamber at low pressures $^{3-6}$ and in open air at atmospheric pressure. $^{7-12}$ Much has been learnt of the bactericidal capability and related physical mechanisms of low-temperature plasmas. ${ }^{13}$ By contrast, there are very few reports on their ability to destruct proteinaceous matters ${ }^{14-16}$ and all reported are limited to the use of vacuum plasmas. More significantly, medical sterilization involves both bacterial inactivation and protein destruction. It is therefore essential to study the protein destruction capability of low-temperature gas discharges before they can be widely accepted as a viable hospital sterilization technique. In this letter, we report an investigation of protein destruction by atmospheric pressure glow discharges (APGDs). Given that plasma protein destruction is in its infancy, the focus of this study is to answer two basic questions: (a) whether APGD can reduce proteins deposited on stainless steel surfaces and (b) whether remaining surface proteins after APGD treatment are damaged.

The atmospheric plasma system used in our study was essentially a cold atmospheric plasma jet. As shown in Fig. 1 , it has a dielectric tube wrapped with a metallic strip as the

\footnotetext{
a) Author to whom correspondence should be addressed; electronic mail:
} m.g.kong@lboro.ac.uk powered electrode. The ground electrode was essentially the sample holder at $10 \mathrm{~mm}$ from the dielectric tube. While its geometric details are given elsewhere, ${ }^{17,18}$ its tubular structure and its use of dielectric barriers are different from the atmospheric pressure plasma jet, ${ }^{19}$ the plasma needle, ${ }^{20}$ and the plasma plume produced from a gas flow through two parallel-plate electrodes. ${ }^{21}$ For future reference, it is referred to as the atmospheric dielectric-barrier discharge (DBD) tube jet or DBD-tube jet. For this study, the DBD-tube jet employed either helium or helium-oxygen mixture as the background gas. Helium flow rate was fixed at $5 \mathrm{slm}$ (standard liters per minute), mixed either with or without an oxygen flow of 25 SCCM (SCCM denotes cubic centimeter per minute at STP). The DBD-tube jet was energized by a $30 \mathrm{kHz}$ sinusoidal power supply with a peak voltage of $8 \mathrm{kV}$. Stainless steel balls of $2 \mathrm{~mm}$ diameter and stainless steel disks of $6 \mathrm{~mm}$ diameter were used to model surgical instruments. Bovine serum albumin (BSA) was used as a model protein. Quantities of BSA were diluted in distilled water and then their droplets were deposited on stainless steel surfaces to dry before plasma treatment. All data were triplicates from three independent experiments.

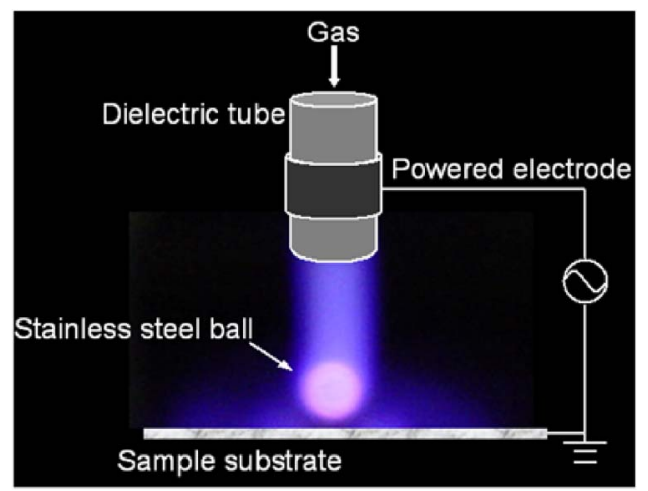

FIG. 1. (Color online) Schematic of the atmospheric DBD-tube jet with a digital image of a stainless steel ball immersed in the jet plume. 


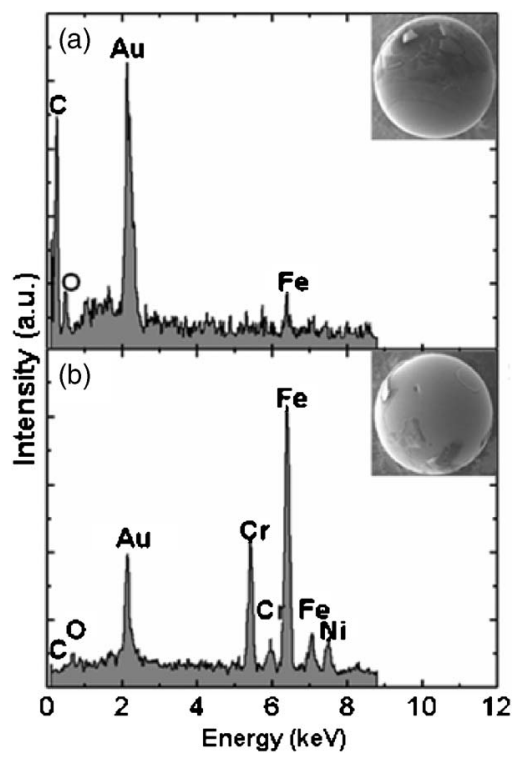

FIG. 2. EDX profiles and SEM images of the BSA-coated stainless steel ball (a) before plasma treatment and (b) after 3 min of plasma treatment.

No commercial techniques are currently available to detect solid proteins deposited on stainless steel surface. As a first attempt to measure protein reduction, we employed scanning electron microscope (SEM) for inspecting any protein fragment and also electron energy dispersive x-ray analysis (EDX) for obtaining the elemental composition of protein-contaminated surfaces. Like any protein, BSA is composed of amino acids that exhibit significant contents of carbon and oxygen in an elemental analysis such as EDX. Therefore, carbon and oxygen in an EDX graph can be used as a protein fingerprint. ${ }^{15,16}$ Figure 2 shows contamination analysis by the use of SEM images and EDX analyses of a BSA-coated stainless steel ball, before and after plasma treatment. The SEM image of the untreated stainless steel ball in Fig. 2(a) shows a heavy BSA coat, and the EDX analysis from a typical point on the untreated ball surface indicates the presence of carbon and oxygen. To highlight the effect of plasma treatment, the DBD-tube jet was used to treat only the top half of the stainless steel ball for $3 \mathrm{~min}$. As shown in Fig. 2(b), the plasma-treated region was clean and free of clear protein coating. Its cleanliness was confirmed by an enlarged SEM image of the treated area with a spatial resolution of $1 \mu \mathrm{m}$ (not shown). Several points in the plasma-treated area were randomly selected for EDX analyses and the results were consistent from one surface point to another. Figure 2(b) shows a typical EDX profile where substantial reduction of oxygen and carbon is evident. The comparison of the EDX data before and after plasma treatment suggests that much of the BSA coating was removed from the stainless steel surface.

After plasma treatment, the removed BSA protein may have been fragmented into basic chemical elements such as oxygen, nitrogen, carbon, and hydrogen. The unremoved proteins that remained on the stainless steel surface were likely to be less damaged than the removed proteins. Although direct measurement data of possible BSA fragmentation are at present unavailable, insight can be gained by using electrophoresis to analyze the unremoved BSA proteins. To this end, buffer-diluted BSA droplets were first deposited on stainless steel disks and then carefully washed off the disks so that they can be collected in equal amounts of buffer

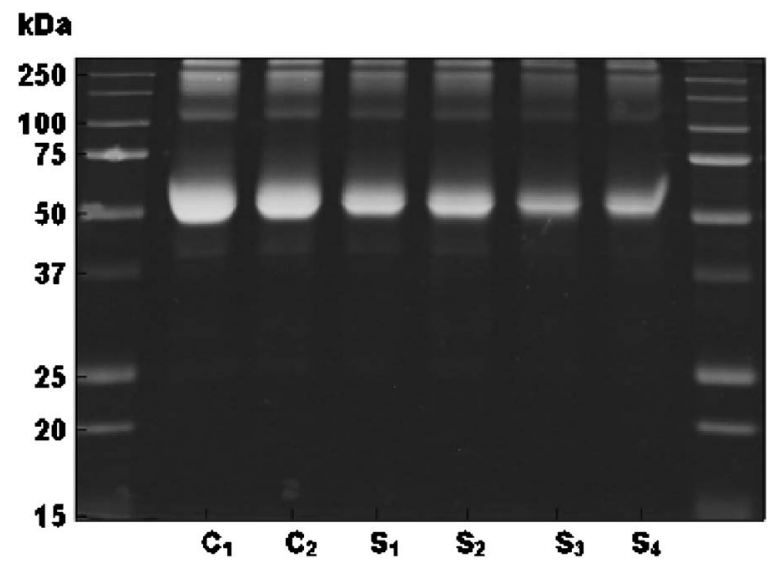

FIG. 3. Electrophoresis images of six BSA samples. $C_{1}$ and $C_{2}$ are two control samples that were left in open air and treated with an unionized $\mathrm{He}-\mathrm{O}_{2}$ flow, both for $300 \mathrm{~s} . \mathrm{S}_{1}, \mathrm{~S}_{2}, \mathrm{~S}_{3}$, and $\mathrm{S}_{4}$ are samples that were treated by the DBD-tube jet for $4,60,180$, and $300 \mathrm{~s}$, respectively.

solution for subsequent electrophoresis experiments. Triplicate experiments were performed to ensure the consistency of electrophoresis results. Figure 3 shows images of two controls $-\mathrm{C}_{1}$ samples were left in open air for $300 \mathrm{~s}$ and $\mathrm{C}_{2}$ samples were treated with a $\mathrm{He}-\mathrm{O}_{2}$ flow also for $300 \mathrm{~s}$. Their electrophoresis images do not show any significant difference from one another. When plasma treatment was applied in four different durations (e.g., 4, 60, 180, and 300 s), the $50 \mathrm{kDa}$ band became progressively thinner and weaker, as shown in Fig. 3. This suggests that the plasma-treated but unremoved proteins underwent considerable degradation. Two useful conclusions may be drawn from this. Firstly, proteins removed from the stainless steel were likely to have sustained much greater damages, destructed potentially into basic chemical elements, than the unremoved proteins. Secondly for protein residues remained on the sample surface, their integrity was compromised. Therefore even when plasma treatment cannot completely remove all proteinaceous matters from stainless steel surfaces, the plasmatreated but unremoved proteins are likely to have a reduced infectivity, if any, and pose less risk than untreated proteins.

Reduction of oxygen and carbon after plasma treatment in Fig. 2 suggests that cold atmospheric pressure discharges are capable of effectively removing protein from stainless steel surfaces. However, SEM and EDX are inappropriate as a quantitative tool for surface protein detection and hence for characterizing the efficiency of plasma protein removal. As most commercial detection techniques are useful for protein in solution only, we employed a laser-induced fluorescence technique $^{22}$ and developed an optical system to detect proteinaceous matters on solid surfaces. As shown in the inserted schematic in Fig. 4, a BSA sample labeled with FITC (fluorescein isothiocyanate) was irradiated by a laser beam at about $488 \mathrm{~nm}$ and the induced fluorescence emission was at $530 \mathrm{~nm}$. With careful choices of the laser, filters, lens, and the dichroic cube, prequantified BSA was found to correlate linearly to the emission intensity at $530 \mathrm{~nm}$ from 55 to 0.1 pmole. Through extrapolation, the detection limit may be lowered to 0.05 pmole. Further calibration was performed using a FluoroMax Pro system. Hence the fluorescence system in Fig. 3 offers a way to detect surface protein quantitatively.

With the surface protein detection technique developed, we performed a series of protein removal experiments using 


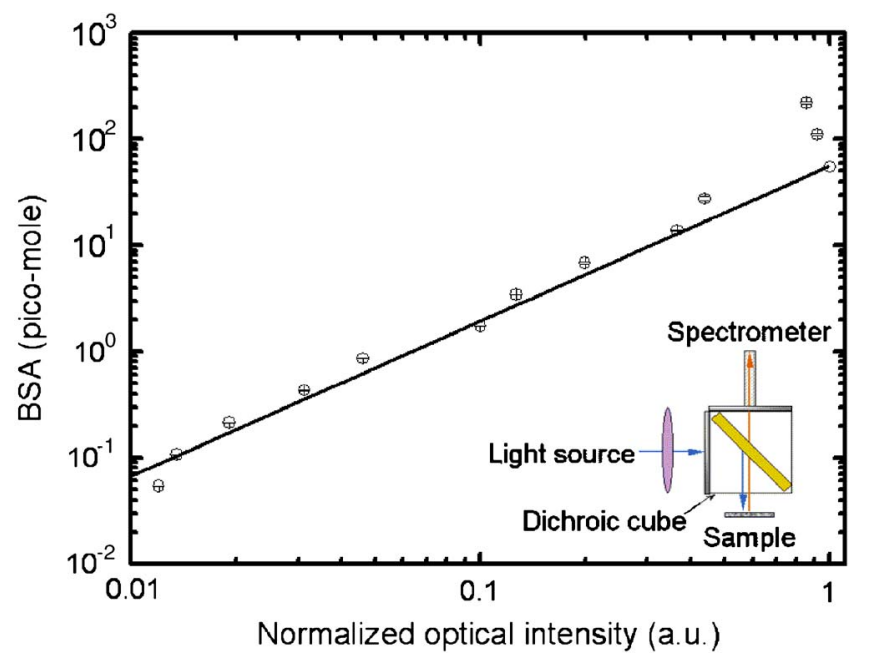

FIG. 4. (Color online) Linear relationship of BSA proteins with the optical intensity of their FITC-labeled fluorescence emission at $530 \mathrm{~nm}$. The inserted diagram illustrates the schematic of the fluorescence detection system.

BSA-coated stainless steel disks and the DBD-tube jet. Figure 5 shows rapid protein reduction for both the helium case and the $\mathrm{He}-\mathrm{O}_{2}$ case, marked as "He" and " $\mathrm{He}-\mathrm{O}_{2}$," respectively to the left vertical axis. Temperature measurements for the $\mathrm{He}$ case and the $\mathrm{He}-\mathrm{O}_{2}$ case (marked as $\mathrm{He}$ and $\mathrm{He}-\mathrm{O}_{2}$, respectively) were made with a thermocouple attached to the sample holder and are shown with the right vertical axis in Fig. 5. With $300 \mathrm{~s}$ of plasma treatment, the sample holder and hence the sample were heated up to 55 and $40{ }^{\circ} \mathrm{C}$ by the $\mathrm{He}$ plasma jet and the $\mathrm{He}-\mathrm{O}_{2}$ plasma jet, respectively. Control experiments were performed using an unionized $\mathrm{He}-\mathrm{O}_{2}$ flow at $5 \mathrm{slm}$ and with the sample temperature kept at $55^{\circ} \mathrm{C}$. This is shown by the curve marked with "flow" in Fig. 5. As $55^{\circ} \mathrm{C}$ was the highest temperature to which the sample holder was heated by plasma treatment, the very slight drop of the control curve in Fig. 5 suggests that heat played very minor role in the observed protein reduction. With the $\mathrm{He}-\mathrm{O}_{2}$ flow, the initial protein reduction was more rapid and the final protein was less than those found for the He flow case. The final amount of the BSA protein left on the stainless steel disks was 0.06 pmole after $300 \mathrm{~s}$ plasma treatment

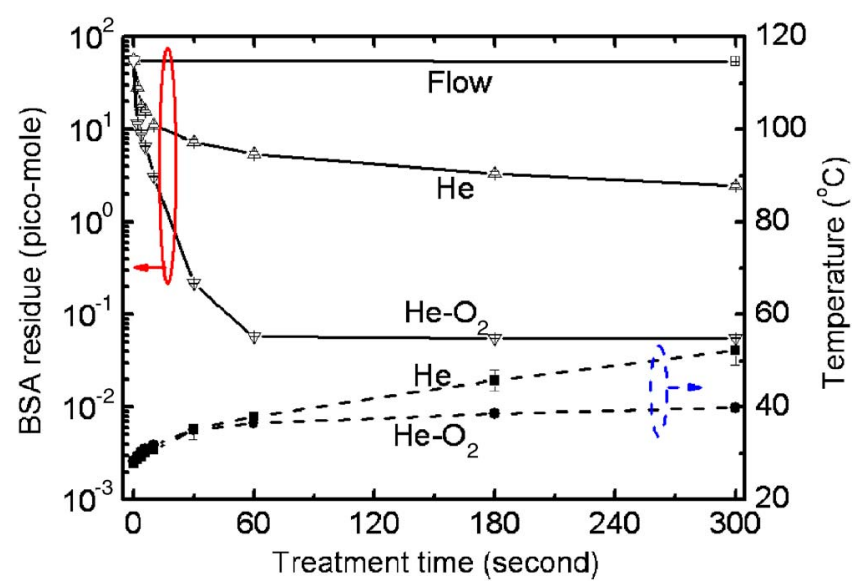

FIG. 5. (Color online) BSA reduction kinetics with the DBD-tube jet in a $\mathrm{He}$ flow (marked with "He") and a $\mathrm{He}-\mathrm{O}_{2}$ flow (marked with "He- $\mathrm{O}_{2}$ "), together with temperature measurement in the He plasma jet (marked with $\mathrm{He}$ ) and in the $\mathrm{He}-\mathrm{O}_{2}$ plasma jet (marked with $\mathrm{He}-\mathrm{O}_{2}$ ). The curve marked with "flow" is BSA reduction curve with an unionized He flow at $55^{\circ} \mathrm{C}$. using $\mathrm{He}-\mathrm{O}_{2}$ or about three $\log$ reductions over $300 \mathrm{~s}$. It is worth mentioning that any protein less than 0.05 pmole would fall below our current detection limit. Hence, the three $\log$ reduction over $300 \mathrm{~s}$ may be limited by protein detection rather than plasma removal.

In summary, we used a DBD-tube jet to study atmospheric plasma removal of proteinaceous matters from stainless steel surfaces. With a wide range of physical techniques including SEM images, EDX analysis, electrophoresis experiments, fluorescence spectroscopy, and inactivation kinetics, it was demonstrated that plasma-treated proteins were either removed from a stainless steel surface as fragments or damaged significantly if remained on the surface. Thermal effects were shown to play a minor role. Given the established ability of the cold atmospheric plasma jet to inactivate bacterial spore ${ }^{17}$ and biofilm-forming bacteria, ${ }^{11}$ the above observations support critically the prospect of cold atmospheric plasmas as a generic sterilization technique capable of both bacterial inactivation and protein destruction.

The authors thank the financial support of the Department of Health and the discussions on fluorescence detection of proteins with J. S. Barton, P. R. Richardson, and A. C. Jones.

${ }^{1}$ P. Brown, M. Preece, J. P. Brandel, T. Sato, L. McShane, I. Zerr, A. Fletcher, R. G. Will, M. Pocchiari, N. R. Cashman, J. H. d'Aignaux, L. Cervenakova, J. Fradkin, L. B. Schonberger, and S. J. Collins, Neurology 55, 1075 (2000).

${ }^{2}$ A. P. Krueger and E. J. Reed, Science 193, 1209 (1976).

${ }^{3}$ C. L. Nelson and T. J. Berger, Curr. Microbiol. 18, 275 (1989).

${ }^{4}$ S. Hury, D. R. Vidal, F. Desor, J. Pelletier, and T. I. Lagarde, Lett. Appl. Microbiol. 26, 417 (1998).

${ }^{5}$ S. Moreau, M. Moisan, M. Tabrizian, J. Barbeau, J. Pelletier, A. Ricard, and L'H. Yahia, J. Appl. Phys. 88, 1166 (2000).

${ }^{6}$ S. Villeger, A. Ricard, and M. Sixou, Eur. Phys. J.: Appl. Phys. 26, 203 (2004).

${ }^{7}$ M. Laroussi, IEEE Trans. Plasma Sci. 30, 1409 (2002).

${ }^{8}$ K. Kelly-Wintenberg, T. C. Montie, C. Brickman, J. R. Roth, A. K. Carr, K. Sorge, L. C. Wadsworth, and P. P. Y. Tsai, J. Ind. Microbiol. Biotechnol. 20, 69 (1998).

${ }^{9}$ H. W. Herrmann, I. Henins, J. Park, and G. S. Selwyn, Phys. Plasmas 6, 2284 (1999)

${ }^{10}$ A. Sharma, A. Pruden, Z. Yu, and G. J. Collins, Environ. Sci. Technol. 39, 339 (2005).

${ }^{11}$ M. Vleugels, G. Shama, X. Deng, E. Greenacre, T. Brocklehurst, and M. G. Kong, IEEE Trans. Plasma Sci. 33, 824 (2005).

${ }^{12}$ T. Sato, T. Miyahara, A. Doi, S. Ochiai, T. Urayama, and T. Nakatani, Appl. Phys. Lett. 89, 073902 (2006).

${ }^{13}$ X. T. Deng, J. J. Shi, and M. G. Kong, IEEE Trans. Plasma Sci. 34, 1310 (2006).

${ }^{14}$ A. Mohul, A. A. Bol'shakov, S. L. Chan, R. M. Stevens, B. N. Khare, M. Meyyappan, and J. D. Trent, Biotechnol. Prog. 19, 776 (2003).

${ }^{15}$ A. G. Whittaker, E. M. Graham, R. L. Baxter, A. C. Jones, P. R. Richardson, G. Meek, G. A. Campbell, A. Aitken, and H. C. Baxter, J. Hosp. Infect. 56, 37 (2004).

${ }^{16}$ H. C. Baxter, G. A. Campbell, A. G. Whittaker, A. C. Jones, A. Aitken, A. H. Simpson, M. Casey, L. Bountiff, L. Gibbard, and R. L. Baxter, J. Gen. Virol. 86, 2393 (2005).

${ }^{17}$ X. T. Deng, J. J. Shi, G. Shama, and M. G. Kong, Appl. Phys. Lett. 87, 153901 (2005)

${ }^{18}$ J. L. Walsh, J. J. Shi, and M. G. Kong, Appl. Phys. Lett. 88, 171501 (2006).

${ }^{19}$ A. Schutze, J. Y. Jeong, S. E. Babayan, J. Park, G. S. Selwyn, and R. F. Hicks, IEEE Trans. Plasma Sci. 26, 1685 (1998).

${ }^{20}$ I. Kieft, E. P. van der Laan, and E. Stoffels, New J. Phys. 6, 149 (2004).

${ }^{21}$ M. Laroussi and X. Lu, Appl. Phys. Lett. 87, 113902 (2005).

${ }^{22}$ V. I. Kovalev, J. S. Barton, P. R. Richardson, and A. C. Jones, Second International Conference on Optical and Laser Diagnostics, London, UK, September 2005 (unpublished). 